\title{
Integrating the Taguchi Method and Response Surface Methodology for Process Parameter Optimization of the Injection Molding
}

\author{
Yung-Tsan Jou', Wen-Tsann Lin ${ }^{2}$, Wei-Cheng Lee ${ }^{1}$ and Tsu-Ming Yeh ${ }^{3, *}$ \\ ${ }^{1}$ Department of Industrial and Systems Engineering, Chung Yuan Christian University, Taiwan \\ 2 Department of Industrial Engineering and Management, National Chin-Yi University of Technology, Taiwan \\ ${ }^{3}$ Department of Industrial Engineering and Management, Dayeh University, Taiwan
}

Received: 13 Jun. 2013, Revised: 18 Oct. 2013, Accepted: 19 Oct. 2013

Published online: 1 May. 2014

\begin{abstract}
The outer coating of an optical fiber cable protects the optical fiber, and the contraction rate of the outer coating can affect the communication capacity and distance, so the contraction rate is often regarded as the key factor in defining the quality of an optical fiber cable. For this reason, using the example of the circular single-pin optical fiber cable manufacturing process of the largest optical communication manufacturer in the world, the Taguchi Method (TM) is used to screen the variables that have significant effects on the contraction rate of the outer coating. Furthermore, the optimization engineering of Response Surface Methodology (RSM) is utilized for the empirical research to acquire a prediction model that can be used to optimize the optical fiber outer coating injection molding process. The research results show that the contraction rate predicted by the integration of the Taguchi Method and RSM is $2.28 \%$. The empirical results reveal that the contraction rate of the outer coating indeed decreased from the original $3.83 \%$ down to $2.16 \%$, indicating that the integration of the Taguchi Method and RSM could effectively improve the quality.
\end{abstract}

Keywords: Taguchi Method, Response Surface Methodology, Parameter Optimization

\section{Introduction}

An optical fiber cable is regarded as a tool to achieve optical conduction by applying the Total Reflection Theory for a fiber made of glass or plastic materials. Optical fiber communication facilitates long-distance transmission at high speeds and is able to avoid electromagnetic interference (EMI) while providing low transmission loss, high secrecy, and high bandwidth. Optical fibers are used in long-distance videotext systems, telephones, the Internet, and computer data transmission. In recent years, the development of multimedia transmission media, such as FTTB (Fiber To The Premises), FTTH (Fiber To The Home), and LANs (Local Area Networks), has resulted in an increasing demand for optical fiber cable. Therefore, the optical fiber cable connection technology is becoming more critical [1].

Circular single-pin optical fiber cable is the most commonly and widely applied indoor optical fiber cable, and it is often used in various device components, instrument panels, and the pigtails and patch cords for equipment. Nevertheless, the outer coating of assembled patch cords is fixed on metal components so that the optical fiber cannot contract and shorten when the outer coating contracts, but this slightly bends the outer coating, which causes optical signal loss and affects the communication capacity and transmission distance of the cable. For this reason, the contraction rate of the optical fiber outer coating has been defined as the key factor in determining the quality of the cable. Because of the increasing competition within the global market, enterprises have come to expect higher-quality products [2].

In the industries related to optical fiber communication, the Taguchi Method is the most commonly used experimental design because exploring the many experimental parameters identified by traditional experimental designs would increase the number of experimental runs and require too many valuable resources, such as money and time, to be spent.

\footnotetext{
*Corresponding author e-mail: tmyeh@mail.dyu.edu.tw
} 
Comparatively, the Taguchi Method makes it possible to identify an optimal value from the preset factor levels with fewer experiments and in a shorter period of time. Nonetheless, the value of the optimal level acquired with the Taguchi Method might not be the global optimum [3]. As a result, parameter optimization is necessary. Many researchers, including Yoo et al. [4], Wang et al. [5], and Ne?eli et al. [6], have applied Response Surface Methodology (RSM) to plan experiments and improve the quality of products in the past few years. This approach not only reduces the experimental costs and time but also identifies the optimal process parameters that can reduce the variability of product quality. However, the key factors from among the experimental variables are not identified with RSM. By integrating the experimental design methods of the Taguchi Method and RSM, the former is utilized for screening the primary variables affecting the contraction rate of the optical fiber outer coating, and the optimization engineering of the latter is applied to planning the experiments and verifying the variables screened with the Taguchi Method to identify the optimal process parameter composition.

\section{Literature Review}

The Taguchi Method and RSM are often independently utilized to develop new products and to improve quality. Nevertheless, these two experimental design methods appear to have significant differences in terms of efficiency and additivity.

\subsection{Taguchi Method}

The Taguchi Method, transformed from traditional experimental design methods, was developed by Dr. Taguchi Genichi in 1949. He wanted to reduce the number of experiments and effectively examine problems in the research and development of communication systems [7]. Such a unique experimental design method could be used to improve the process and product design by combining orthogonal arrays with simple function computation. Taguchi et al. [8] indicated that the Taguchi Method uses parameter design to improve the quality by defining the target functions aiming at the quality required for improvement, identify the factors and levels in the target functions, and apply orthogonal arrays to determine the allocation of experimental factors and the number of times so that fewer experiments are needed to acquire the same information obtained in full-factorial experiments. As a result, little experimental data needs to be analyzed to effectively improve product quality. Julie et al. [9] noted that Orthogonal Arrays and S/N Ratios are the major tools used in the Taguchi Method and emphasized the consideration of quality in product and process design. In other words, the emphasis was on reducing the variability of product performance by utilizing ANOVA to understand the effects of various significant factors in tolerance design and further setting the tolerance of different significant factors based on the costs of the significant factors to acquire the best quality and most robust design. Utilizing engineering knowledge to plan the experiments, the Taguchi Method focuses on finding a solution to achieve the objectives. The experimental results of Taguchi's experimental design method have the following advantages: high reproducibility, easy identification of the experimental variables, a reduced number of experiments, and easily understood analyses. The Taguchi Method therefore has been utilized for improving the industry and optimizing parameter design. For instance, Su et al. [10] effectively enhanced optical whiteness with Taguchi's Dynamic Approach, Hong [11] identified the key factors in the market segment with the Taguchi Method, and Souza et al. [12] applied the Taguchi Method to improving the quality of hemodialysis. By computing the target function and transforming it into a Signal-to-Noise ratio, the Signal-to-Noise ratio of the quality characteristics is divided into the Larger the Better, Nominal the Better, and the Smaller the Better in the definition of Taguchi Method. This study aims to decrease the contraction rate of optical fiber outer coatings; the smaller the contraction rate, the better the communication capacity and transmission distance. In this case, the Smaller the Better (STB) is used to compute the Signal-to-Noise ratio of the contraction rate, as shown in equation (1).

$$
S N_{S T B}=-10 \cdot \log _{10}\left(\frac{1}{n} \sum_{i=1}^{n} y_{i}^{2}\right)
$$

where $y_{i}$ is the performance response to the $i$ th setting of the parameter combination, and $n$ is the number of samples for the performance response corresponding to the number of design parameter combinations. The variability is inversely proportional to the $\mathrm{S} / \mathrm{N}$ ratio, meaning that a larger $\mathrm{S} / \mathrm{N}$ ratio corresponds to a more robust system. Following the analysis of variance (ANOVA), the experimental results are acquired by independently extracting the main effects of these factors and determining the statistically significant factors. This process identi?es the controlling factors and optimizes the magnitude of the effects accordingly. Although the Taguchi Method can be used to screen the key factors from the experimental factors and to determine an optimum from the preset factor levels, such values are not necessarily the global optimum [13]. For this reason, a parameter optimization study is required.

\subsection{Response Surface Methodology (RSM)}

Different from the Taguchi Method, Response Surface Methodology basically combines statistical and experimental methods with data-fitting techniques. Based 
on the responses acquired in the experiments, Regression Analysis is utilized to identify the relationships between the responses and the variables to establish a mathematical model that satisfies the relationship between a group of test factors and objective functions. This model is then used to explore the optimal solution in the experimental area [14][15]. Because of its practicability, favorable efficiency, and ease of implementation, RSM has been widely applied to various industries, such as chemical engineering, semiconductors, electronics manufacturing, machining, and metal cutting. Bappa et al. [16] applied RSM to rapidly identify the optimal welding set for laser transmission welding. Paventhan et al. [17] utilized Response Surface Methodology to design their experiments and established a Regression Model to identify the optimal welding parameters and efficiently determine the effects of various factors on the quality. Rajamurugan et al. [18] applied RSM to the modeling and analysis of thrust force in the drilling of GFRP Composites to identify the optimal setting for reducing the processing time and significantly enhancing the production rate. Another important issue for Response Surface Methodology is explaining the shape of the Response Surface based on the relationships between the responses and independent variables. When the independent variables change values in certain directions, the responses should also change [19]. In other words, RSM tends to focus on the relationships between multiple factors $\left(x_{1}, x_{2}, x_{3}, \ldots, x_{k}\right)$ and the response (quality) $y$. Consequently, the functional relationship between the responses and the independent variables should first be determined to produce a proper approximating function, and then the factor setting levels $\left(x_{i}\right)$ needed to obtain the optimal response should be identified. The relationship between the response variables and the independent variables (factors) can be presented in the form of equation (2).

$$
y=f\left(x_{1}, x_{2}, x_{3}, \ldots, x_{k}\right)
$$

where $f$ is a multivariate function, the items represent the factors (independent variables), and the relationship describes a curved surface $y=f\left(x_{1}, x_{2}, x_{3}, \ldots, x_{k}\right)$ that is known as a Response Surface.

Equation (3) and (4) are First-Order and Second-Order Response Surfaces, respectively.

$$
\begin{gathered}
y=\beta_{0}+\beta_{1} x_{1}+\beta_{2} x_{2}+\ldots++\beta_{k} x_{k}+\varepsilon \\
y=\beta_{0} x_{0}+\sum_{i=1}^{k} \beta_{i} x_{i}+\sum_{i=1}^{k} \beta_{i i} x_{i}^{2}+\sum_{i<j} \sum \beta_{i j} x_{i} x_{j}+\varepsilon
\end{gathered}
$$

A Response Surface is analyzed through the fitting surface, and the analysis of the fitting surface is regarded as an analysis of the real system when the fitting surface thoroughly describes the response function. Generally, Response Surface Methodology utilizes First-Order and
Second-Order models; the Second-Order model would be used in cases in which the First-Order model is not suitable [19]. When selecting fitting experiments requiring Second-Order RSM, Central Composite Design (CCD) experiments are normally performed. CCD was developed by Box and Wilson [20] and improved by successive researchers. Because Second-Order fitting with CCD provides favorable predictions, the fitting model shows consistent and stable variance for the prediction of any input point. CCD combines the original fractional factorial or full factorial design with axial runs and center points to produce Central Composite Design experiments. Including axial runs in the design is done to introduce quadratic terms in the model, while the inclusion of center points tends to test the curvature of the response surface. In the beginning of the solving procedure, a starting point is selected as the experimental center for the CCD factorial fitting experiments. Regression Analysis is applied to the experimental results to find a suitable model. A Desirability Function is further applied to acquire the optimal processing parameter composition and operating window.

\section{Research Methods}

The Taguchi Method was first utilized to screen variables that appeared to have significant effects on the quality. RSM was further used to optimize the screened variables and to determine the operating window by identifying the optimal process parameter composition. The steps are described below. 1. Determine experimental variables and levels: The experimental variables and levels were selected according to the required parameters and the range for the process. 2. Design and run experiment: The Taguchi Method was applied to the experiments and data were recorded. 3. Screen key independent variables: By analyzing the experimental variables with ANOVA and testing and calculating the percent contribution, the variables that appeared to have significant effects on the quality were identified, and the ideal contraction ratio was predicted. 4. Create response surface design and run experiment: The screened variables with notable effects were further investigated using CCD experiments with RSM. The data were analyzed, and the fitting model was applied to study the interactions among factors; isopleths and a response surface map were used for in-depth investigation of the Response Surface System to identify the process region that produced the optimal responses. 5 . Optimization: A Desirability Function was utilized to determine the operating window necessary to acquire the optimal composition and to predict the ideal contraction ratio, which were further compared with the predictions from the Taguchi Method. 6. Confirmation tests: The optimal composition predicted by the response surface design was tested with confirmation experiments, and the results were compared with the prediction results from the Taguchi Method and RSM 


\section{Case Study}

\subsection{Determine experimental variables and levels}

The key process used to form optical fiber cable involves melting plastic for take-up (Figure 1). Six factors (experimental variables) were selected that effect the key processing procedure used to form optical fiber cable (Figure 1). The levels were selected by the process managers, engineers, and quality assurance personnel from the optical fiber cable manufacturer. The required parameters and the range for the present optical fiber cable process were analyzed and discussed. The settings chosen for the experimental variables and levels are shown in Table 1.

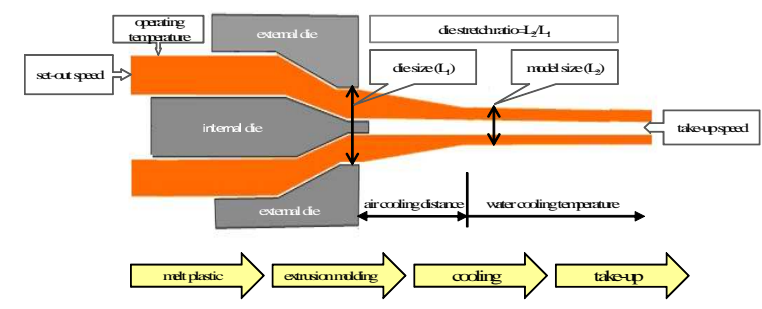

Fig. 1: Key processing procedure used to form optical fiber cable.

\subsection{Design and run experiment}

Table 2 shows the orthogonal array and the associated experimental results for the contraction rate with the calculated $\mathrm{S} / \mathrm{N}$ ratios. The data analysis were mainly applied to screening the experimental variables with significant effects on the quality, so the interactions among variables are not discussed in this study.

\subsection{Screen key independent variables}

Variables with remarkable effects on the quality were screened by analyzing the experimental variables with ANOVA and testing and calculating the percent contribution.

\subsubsection{Analysis of experiment factors}

Analysis of the influence of each experiment factor (A, B, $\mathrm{C}, \mathrm{D}, \mathrm{E}$, and F) on the contraction rate were performed with a so-called $\mathrm{S} / \mathrm{N}$ response table, using the Minitab 16 software package. Table 3 shows the orthogonal array and the associated experimental results for the contraction rate with the calculated $\mathrm{S} / \mathrm{N}$ ratio. The $\mathrm{S} / \mathrm{N}$ response table for the contraction rate is presented in Table 3. It shows the calculated $\mathrm{S} / \mathrm{N}$ ratios of experimental factors in each level. The experimental factor with the strongest influence was determined depending on the value of delta, as shown in Table 3. Delta equals the difference between the maximum and the minimum $\mathrm{S} / \mathrm{N}$ ratios for a particular experimental factor. The higher the value of delta, the more influential the experimental factor. The experimental factors and their interactions were sorted according to the values of delta.

Referring to Lee [21], Sheu [22], and Yang [23], the experimental factors with a value of delta larger than the mean effect were selected as the key factors in this study. From Tables 3 and 4, the strongest influence was exerted by the air cooling distance (factor D) and the operating temperature (factor $\mathrm{B}$ ), respectively, meaning that the response table presented in Table 4 also gave the same results for the influence of the factors.

The plots for the $\mathrm{S} / \mathrm{N}$ ratio are shown in Figure 2. The optimal levels for each experimental factor could be easily determined from these graphs in accordance with Taguchi's "the smaller the better" performance characteristic. The response graphs showed the variation of the $\mathrm{S} / \mathrm{N}$ ratio when the setting of the experiment factors was changed from one level to another. Figure 2 suggests that the optimal settings for obtaining the minimum contraction rate involve the following combination of the experimental factors: A1, B2, C2, D1, E1, and F2 levels.
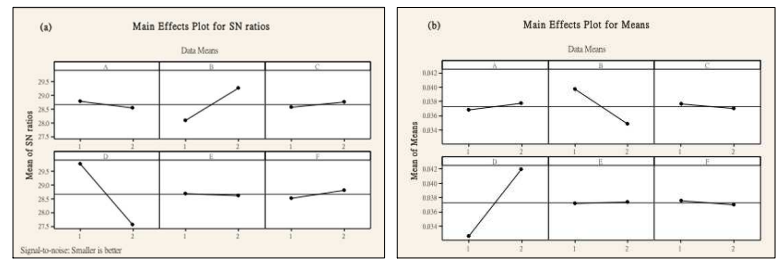

Fig. 2: Main effect plots for contraction rate: (a) $\mathrm{S} / \mathrm{N}$ ratio and (b) mean.

\subsubsection{ANOVA}

ANOVA was used to investigate which design parameter significantly affected the quality characteristic. ANOVA was performed by separating the total variability of the $\mathrm{S} / \mathrm{N}$ ratio into contributions from each of the design parameters and the errors. The total variability of the $\mathrm{S} / \mathrm{N}$ ratio was measured by the sum of the squared deviations from the total mean S/N ratio. Su et al. [10], Chen and Ou [24], and Souza et al. [12] applied P test values to proceed with the decision-making process. The $\mathrm{P}$ value was calculated for each design parameter. Usually, when the $\mathrm{P}$ value is $>0.05$, the related design parameter appears to 
Table 1: Experiment factors and levels

\begin{tabular}{|c|c|c|c|c|}
\hline code & Experimental variables & \multicolumn{3}{|c|}{ Level in coded form } \\
\hline & & 1 & 2 & Units \\
\hline A & Die stretch ratio & 1.5 & 2.1 & R \\
\hline B & Operating temperature & 162.0 & 175.0 & ${ }^{\circ} \mathrm{C}$ \\
\hline C & Water cooling temperature & 25.0 & 35.0 & ${ }^{\circ} \mathrm{C}$ \\
\hline D & Air cooling distance & 10.0 & 35.0 & $\mathrm{~cm}$ \\
\hline E & Take-up speed & 20 & 40 & $\mathrm{~m} / \mathrm{min}$ \\
\hline F & Set-out speed & 20 & 40 & $\mathrm{~m} / \mathrm{min}$ \\
\hline
\end{tabular}

Table 2: Experimental design using L8 orthogonal array and response value

\begin{tabular}{|c|c|c|c|c|c|c|c|c|}
\hline Run Order & $\begin{array}{c}\text { Die } \\
\text { Stretch } \\
\text { ratio }\end{array}$ & $\begin{array}{c}\text { Operating } \\
\text { temperature }\end{array}$ & $\begin{array}{c}\text { Water } \\
\text { cooling } \\
\text { temperature }\end{array}$ & $\begin{array}{c}\text { Air } \\
\text { cooling } \\
\text { distance }\end{array}$ & $\begin{array}{c}\text { Take-up } \\
\text { speed }\end{array}$ & $\begin{array}{c}\text { Set-up } \\
\text { speed }\end{array}$ & $\begin{array}{c}\text { Contraction } \\
\text { Rate }\end{array}$ & S/N Ratios \\
\hline 1 & 1 & 1 & 1 & 1 & 1 & 1 & 0.0352 & 29.0691 \\
\hline 2 & 1 & 1 & 1 & 1 & 2 & 2 & 0.0440 & 27.1309 \\
\hline 3 & 1 & 2 & 2 & 1 & 1 & 2 & 0.0289 & 30.7820 \\
\hline 4 & 1 & 2 & 2 & 2 & 2 & 1 & 0.0391 & 28.1565 \\
\hline 5 & 2 & 1 & 2 & 1 & 2 & 1 & 0.0355 & 28.9954 \\
\hline 6 & 2 & 1 & 2 & 2 & 1 & 2 & 0.0442 & 27.0916 \\
\hline 7 & 2 & 2 & 1 & 1 & 2 & 2 & 0.0308 & 30.2290 \\
\hline 8 & 2 & 2 & 1 & 2 & 1 & 1 & 0.0405 & 27.8509 \\
\hline
\end{tabular}

Table 3: $\mathrm{S} / \mathrm{N}$ response table for the contraction rate

\begin{tabular}{|c|c|c|c|c|c|c|}
\hline Level & A & B & C & D & E & F \\
\hline 1 & 28.78 & 28.07 & 28.57 & 29.77 & 28.70 & 28.52 \\
\hline 2 & 28.54 & 29.25 & 28.76 & 27.56 & 28.63 & 28.81 \\
\hline Delta & 0.24 & 1.18 & 0.19 & 2.21 & 0.07 & 0.29 \\
\hline Rank & 4 & 2 & 5 & 1 & 6 & 3 \\
\hline
\end{tabular}

have a significant effect on the quality characteristic; when the $\mathrm{P}$ value for a factor is $>0.05$, that factor is not significant and can be neglected. Hong [11], Hsiang and Lin [25], and $\mathrm{Su}$ and Yeh [3] applied the Percent Contribution to the decision-making process. Percent Contribution equals the ratio of the Pure Sum of Squares (Pure SS) to the Total Sum of Squares (Total SS) of each factor. When the percentage (lerr) of pooled error $\leq 15 \%$, no key factor was lost in the experiment. In other words, the factors in the pooled error terms were not significant and could be neglected. The examination of the calculated $P$ test values and percent contribution for all experiment factors also shows a very high influence of factor B and factor $\mathrm{D}$ on the contraction rate (Table 5).

The $\mathrm{P}$ value was first examined, and the $\mathrm{P}$ values of factors B and D were 0.029 and 0.015 , respectively. Because the $\mathrm{P}$ values were $\leq 0.05$, factors $\mathrm{B}$ and $\mathrm{D}$ could be judged to have significant effects on the contraction rate. In contrast, the $\mathrm{P}$ value of factors $\mathrm{A}, \mathrm{C}, \mathrm{E}$, and $\mathrm{F}>$ 0.05 meant that these factors were not significant and could be neglected. Percent Contribution was further examined: the Percent Contribution of the air cooling distance (factor D) and the operating temperature (factor B) was $21.03 \%$ and $74.95 \%$, respectively. Furthermore, the percentage of the pooled error was $4.02 \%$, revealing that no important factor was being neglected.

Based on the analysis of experimental factors and ANOVA, it was judged that the air cooling distance (factor D) and the operating temperature (factor B) had remarkable effects on the contraction rate.

\subsubsection{Prediction}

Based on the above discussion, the optimal control factor-level combination was set as $B_{2} D_{1}$. Next, the contraction ratio under the optimal combination needed to be predicted. To avoid overestimation, only Factors B and $\mathrm{D}$ were used for calculating the predicted contraction ratio. The average of eight contraction ratios was $\mathrm{T}=$ 0.03728 . The average contraction ratio at $B_{2}$ was $a v \cdot B_{2}=$ 0.03483 , and the average contraction ratio at $D_{1}$ was $a v \cdot D_{1}=0.03260$. The expected contraction ratio at the optimal combination was Contraction ratio $=\mathrm{T}+\left(a v \cdot B_{2}-\right.$ $\mathrm{T})+\left(a v \cdot D_{1}-\mathrm{T}\right)=a v \cdot B_{2}+a v \cdot D_{1}-\mathrm{T}=0.03015$ 
Table 4: Means response table for the contraction rate

\begin{tabular}{|c|c|c|c|c|c|c|}
\hline Level & $\mathrm{A}$ & $\mathrm{B}$ & $\mathrm{C}$ & $\mathrm{D}$ & $\mathrm{E}$ & $\mathrm{F}$ \\
\hline 1 & 0.03680 & 0.03972 & 0.03762 & 0.03260 & 0.03720 & 0.03757 \\
\hline 2 & 0.03775 & 0.03483 & 0.03692 & 0.04195 & 0.03735 & 0.03697 \\
\hline Delta & 0.00095 & 0.00490 & 0.00070 & 0.00935 & 0.00015 & 0.00060 \\
\hline Rank & 3 & 2 & 4 & 1 & 6 & 5 \\
\hline
\end{tabular}

Table 5: Results of the analysis of variance for the contraction rate

\begin{tabular}{|c|c|c|c|c|c|c|c|}
\hline Source & df & SS & MS & F & P values & Pure SS & Contribution (\%) \\
\hline A & 1 & $0.11803^{*}$ & 0.11803 & 20.78 & 0.137 & - & - \\
\hline B & 1 & 2.79816 & 2.79816 & 492.62 & $0.029^{*}$ & 2.7238 & $21.03 \%$ \\
\hline C & 1 & $0.06947^{*}$ & 0.06947 & 12.23 & 0.177 & - & - \\
\hline D & 1 & 9.78090 & 9.78090 & 1721.93 & $0.015^{*}$ & 9.7065 & $74.95 \%$ \\
\hline E & 1 & $0.00993^{*}$ & 0.00993 & 1.75 & 0.412 & - & - \\
\hline F & 1 & $0.16866^{*}$ & 0.16866 & 29.69 & 0.116 & - & - \\
\hline Error & 1 & $0.00568^{*}$ & 0.00568 & & & - & - \\
\hline Pooled error & $(5)$ & $(0.37177)$ & $(0.074354)$ & & & 0.5205 & $4.02 \%$ \\
\hline Total & 7 & 12.9508 & & & & 12.9508 & $100 \%$ \\
\hline
\end{tabular}

\subsection{Create response surface design and run experiment}

Using the Taguchi Method to screen the factors, the air cooling distance and the operating temperature were determined to be the key factors having notable effects on the contraction rate. As a consequence, the air cooling distance and the operating temperature were used in the CCD allocation and experiments with RSM, and isopleths and a response surface map were used to facilitate in-depth discussions of the Response Surface System to identify the regions that would produce the optimal responses.

\subsubsection{Response Surface Methodology (RSM)}

Both the operating temperature and the air cooling distance were regarded as experimental variables for the Central Composite Design (CCD) that was created using the Minitab 16 software package. The experimental allocation, factor levels, and experimental results are shown in Table 6 (value of Alpha $(\alpha)$ face centered).

\subsubsection{Fitting Results of RSM}

For the Response Surface Analysis, the fitness of the established Regression Model should first be confirmed. The significance analysis of the Lack-of-Fit is normally applied to understanding the fitting between regressors and responses. The experimental data in Table 6 were used for the model fitting with the Minitab16 software package. Table 7 shows the Second-Order fitting results, where the $\mathrm{P}$ value of Lack-of-Fit appears to be 0.182 $(>0.05)$, indicating that the Full Quadratic Model did not exhibit Lack-of-Fit; $\mathrm{R}-\mathrm{Sq}=94.45 \%$ revealed that the quadratic model was acceptable as the statistical model.

With $y$ as the contraction rate of the outer coating, A as the operating temperature, and B as the air cooling distance, the relation between the regressors and the response is shown below.

$$
y=4.43002-0.05073 A-0.00532 B+0.00015 A^{2}+
$$
$0.00004 B^{2}$

\subsubsection{Surface plot and contour plot}

Figure 3 shows the contraction ratio of the surface plot vs. the air cooling distance and operating temperature. The curve bent from the surface plot, showing that there was a minimum contraction ratio in the research range. Figure 4 shows the contraction ratio in the form of a contour plot, with the isolines representing distinct levels. From the figure, for an air cooling distance of approximately $20 \mathrm{~cm}$ and an operating temperature of approximately $172{ }^{\circ} \mathrm{C}$, the minimum contraction ratio is lower than $0.025(2.5 \%)$.

\subsection{Optimization engineering}

Box and Behnken [26] proposed a Simultaneous Optimal Solution with a Composite Desirability Function for acquiring the optimal parameter composition. Figure 5 shows the optimal parameter composition and the predicted response acquired by the Desirability Function, where $y$ is the minimum response of the contraction ratio, $d$ is the individual Desirability Function, and D is the Composite Desirability Function for the best opportunity to achieve the objective. This study involves a single response, so the composite desirability and the individual 
Table 6: Experimental configuration and response values for the CCD design

\begin{tabular}{|c|c|c|c|c|}
\hline Std Order & Run Order & Operating Temperature & Air Cooling Distance & Contraction Ratio \\
\hline 7 & 1 & 173.5 & 5.0 & 0.032 \\
\hline 11 & 2 & 173.5 & 17.5 & 0.026 \\
\hline 3 & 3 & 167.0 & 30.0 & 0.028 \\
\hline 12 & 4 & 173.5 & 17.5 & 0.023 \\
\hline 2 & 5 & 180.0 & 5.0 & 0.041 \\
\hline 5 & 6 & 167.0 & 17.5 & 0.028 \\
\hline 13 & 7 & 173.5 & 17.5 & 0.024 \\
\hline 9 & 8 & 173.5 & 17.5 & 0.024 \\
\hline 1 & 9 & 167.0 & 5.0 & 0.036 \\
\hline 8 & 10 & 173.5 & 30.0 & 0.026 \\
\hline 6 & 11 & 180.0 & 17.5 & 0.030 \\
\hline 4 & 12 & 180.0 & 30.0 & 0.040 \\
\hline 10 & 13 & 173.5 & 17.5 & 0.022 \\
\hline
\end{tabular}

Table 7: Experimental configuration and response values for the CCD design

\begin{tabular}{|c|c|c|c|c|c|c|}
\hline Origin & df & Seq SS & Adj SS & Adj MS & F value & P value \\
\hline Regression & 5 & 0.000452 & 0.000452 & 0.000090 & 23.84 & $0.000^{* * *}$ \\
\hline Linear & 2 & 0.000098 & 0.000132 & 0.000066 & 17.48 & $0.002^{*}$ \\
\hline Square & 2 & 0.000342 & 0.000342 & 0.000171 & 45.10 & $0.000^{* * *}$ \\
\hline Interaction & 1 & 0.000012 & 0.000012 & 0.000012 & 3.23 & 0.115 \\
\hline Residual & 7 & 0.000027 & 0.000027 & 0.000004 & & \\
\hline Lack-of-Fit & 3 & 0.000018 & 0.000018 & 0.000006 & 2.69 & 0.182 \\
\hline Pure Error & 4 & 0.000009 & 0.000009 & 0.000002 & & \\
\hline Sum & 12 & 0.000478 & & & & \\
\hline S =0.00194685 R-Sq $=94.45 \%$ R-Sq(adj) $=90.49 \%$ \\
\hline
\end{tabular}

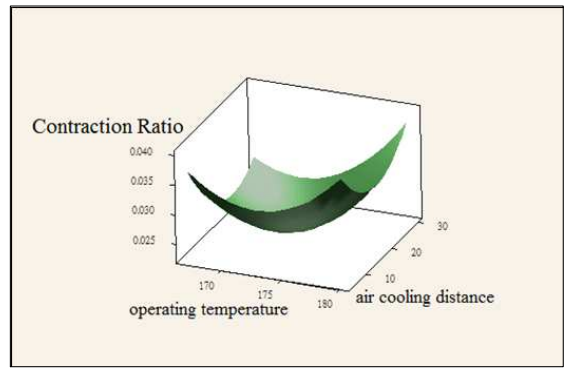

Fig. 3: Surface plot of the contraction ratio as a function of the air cooling distance and the operating temperature.

Desirability Function are the same. With RSM, it was determined that the optimal conditions that should be used to achieve the objective are A (air cooling distance) equal to $20.6566 \mathrm{~cm}$ and $\mathrm{B}$ (operating temperature) equal to $171.5960^{\circ} \mathrm{C}$; these settings will yield a minimum contraction ratio of $2.28 \%$ and a Total Desirability Function D of 1.

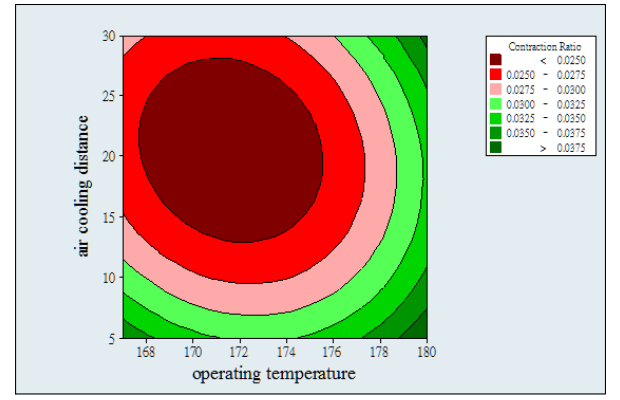

Fig. 4: Contour plot of the contraction ratio as a function of the air cooling distance and the operating temperature.

\subsection{Confirmation tests}

The final step was to carry out a confirmation test. By performing the confirmation test, the conclusions drawn from the analysis were validated. In practice, the air cooling distance and operating temperature could only be specified to the first digit after the decimal point; therefore, the air cooling distance and operating temperature were set at $171.6{ }^{\circ} \mathrm{C}$ and $20.7 \mathrm{~cm}$, respectively. An experiment was conducted using the new combination, and the result was compared with the 


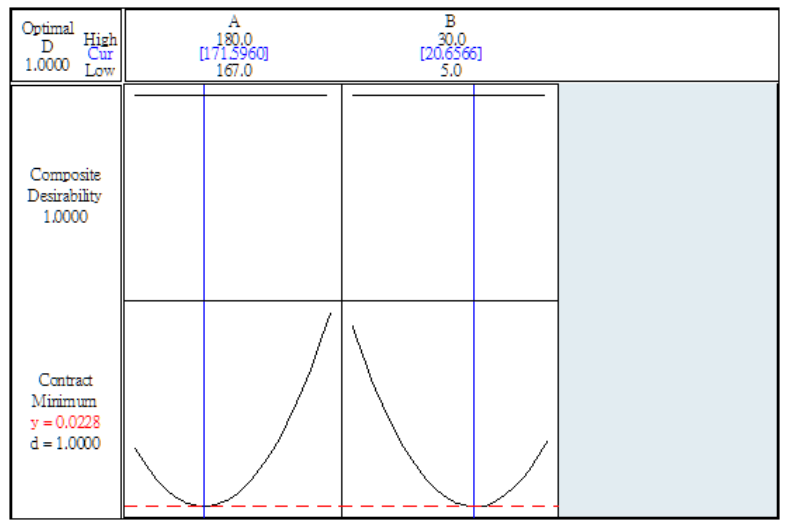

Fig. 5: Optimization of the contraction ratio.

predictions from the Taguchi Method and RSM, as shown in Table 8.

\section{Conclusion}

The stable quality of the outer coating of the optical fiber cable could directly affect the yield rate of the products. By having the process managers, engineers, and quality assurance personnel at the optical fiber cable manufacturer analyze and discuss the selected experimental variables to identify the appropriate parameter settings and ranges for the optical fiber cable process, the Taguchi Method could be applied to identify the key factors affecting the contraction rate of the outer coating of the optical fiber cable from among the experimental variables, and the Central Composite Design from Response Surface Methodology could then be utilized to optimize the process parameters and identify the optimal process parameter settings and responses. Such experimental design methods make it possible to avoid the experiential rules and Trial-and-Error methods that are traditionally used for improvement, further reduce the experimental costs needed to achieve a stable, high-quality process, and improve the yield rate of production. The prediction of the optimal parameter composition acquired by the Taguchi Method is considered to be a limitation in this study. The optimization engineering of RSM is further utilized to verify that the optimal process parameter composition determined by the Taguchi Method is the optimal solution. The results show that the optimization engineering of RSM makes it possible to obtain a minimum contraction rate for the optical fiber cable outer coating of $2.28 \%$, which is better than the optimal solution of $3.015 \%$ obtained with the Taguchi Method. This outcome highlights the feasibility of the integration of the Taguchi Method and RSM. Based on the combined approach involving the Taguchi Method and RSM, the optimal process parameters for the air cooling distance was $20.6566 \mathrm{~cm}$ and for the operating temperature was $171.5960{ }^{\circ} \mathrm{C}$. In practice, the setting of the parameter digit after the decimal point is restricted, so the air cooling distance was set to $20.7 \mathrm{~cm}$, and the operating temperature was set to $171.6{ }^{\circ} \mathrm{C}$. The mean contraction rate of the optical fiber cable outer coating obtained from the experimental confirmation run was $2.16 \%$, which is better than the optimal solution of $2.28 \%$ predicted in this study, indicating that the integration of the Taguchi Method and RSM is practically effective. The case manufacturer therefore should invest in production runs using the specified process parameter composition. The optimization engineering that can be accomplished with RSM and the Taguchi Method should be further investigated. This research can provide relevant practitioners with a reference for applying these techniques in practical and academic research.

The authors are grateful to the anonymous referee for a careful checking of the details and for helpful comments that improved this paper.

\section{References}

[1] TIA Standard, Standard for Optical Fiber Outside Plant Communications Cable, Telecommunications industry association, TIA-472D000-B, (2007).

[2] W. P. Wang, Evaluating new product development performance by fuzzy linguistic computing, Expert Systems with Applications, 36, 9759-9766 (2009).

[3] C. T. Su, C. J. Yeh, Optimization of the $\mathrm{Cu}$ wire bonding process for IC assembly using Taguchi Methods, Microelectronics Reliability, 51, 53-59 (2011).

[4] K. S. Yoo, Y. S. Eom, J. Y. Park, M. G. Im, S. Y. Han, Reliability-based topology optimization using successive standard response surface method, Finite Elements in Analysis and Design, 47, 843-849 (2011).

[5] Y. Wang, C. Huang, T. Xu, Optimization of electrodialysis with bipolar membranes by using response surface nethodology, Journal of Membrane Science, 362, 249254 (2010).

[6] S. Neşeli, S. Yaldiz, E. Türkeş, Optimization of tool geometry parameters for turning operations based on the response surface methodology, Measurement, 44, 580-587 (2011).

[7] G. Box, D. Behnken, Some new three level designs for the study of quantitative variables, Technometrics, 2, 455-475 (1960).

[8] G. Taguchi, S. Chowdhury, Y. Wu, Taguchi's Quality Engineering Handbook, John Wiley \& Sons, (2004).

[9] Z. J. Zhang, J. C. Chen, E. D. Kirby, Surface roughness optimization in an end-milling operation using the Taguchi design method, Journal of Materials Processing Technology, 184, 233-239 (2007).

[10] C. T. Su, C. M. Lin, C. C. Hsu, Optimization of the optical whiteness ratio for flexible display by using Taguchi's dynamic approach, IEEE Transactions on semiconductor manufacturing, 25, 2-15 (2012). 
[11] C. W. Hong, Using the Taguchi Method for effective market segmentation, Expert Systems with Applications, 39, 54515459 (2012).

[12] H. J. Celani de Souza, C. B. Moyses, F. J. Pontes, R. N. Duarte, C.E. Sanches da Silva, F. L. Alberto, U. R. Ferreira, M. B. Silva, Molecular assay optimized by Taguchi experimental design method for venous thromboembolism investigation, Molecular and Cellular Probes, 25, 231-237 (2011).

[13] C. T. Su, C. J. Chou, A systematic methodology for the creation of Six Sigma projects: A case study of semiconductor foundry, Expert Systems with Applications, 34, 2693-2703 (2008).

[14] D. C. Montgomery, H. M. Raymond, Response Surface Methodology: Process and Product Optimization Using Designed Experiments, John Wiley, New York, (2002).

[15] L. Deng, C. S. Cai, Bridge Model Updating Using Response Surface Method and GA, Journal of Bridge Engineering, 15, 553-564 (2010).

[16] A. Bappa, S. K. Arunanshu, M. Souren, M. Dipten, Modeling and analysis of simultaneous laser transmission welding of polycarbonates using an FEM and RSM combined approach, Optics \& Laser Technology, 44, 995-1006 (2012).

[17] R. Paventhan, P. R. Lakshminarayanan, V. Balasubramanian, Prediction and optimization of friction welding parameters for joining aluminum alloy and stainless steel, Transactions of Nonferrous Metals Society of China, 21, 1480-1485 (2011).

[18] T. V. Rajamurugan, K. Shanmugam, S. Rajakumar, K. Palanikumar, Modelling and analysis of thrust force in drilling of GFRP Composites using Response Surface Methodology (RSM), Procedia Engineering, 38, 3757-3768. (2012).

[19] D. C. Montgomery, Design and Analysis of Experiments, 7thed., John Wiley \& Sons, New York, (2009).

[20] G. E. P. Box, K. B. Wilson, On the Experimental Attainment of Optimum Condition, Journal of the Royal Statistic Society, 13, 1-45 (1951).

[21] H. H. Lee, Quality Management, Tsang Hai Book Publishing Co., Taipei., (2009).

[22] S. H. Sheu, The Management and Control of Quality, Future Career Publishing Corporation, Taipei., (2007).

[23] S. F. Yang, Quality Management, Hwa Tai Publishing Co., Taipei., (2006).

[24] F. L. Chen, T. Y. Ou, Sales forecasting system based on Gray extreme learning machine with Taguchi Method in retail industry, Expert Systems with Applications, 38, 1336-1345. (2011).

[25] S. H. Hsiang, Y. W. Lin, Optimization of the extrusion process for magnesium alloy sheets using the fuzzy based Taguchi Method, The Arabian Journal for Science and Engineering, 34, 175-185. (2009).

[26] G. E. P. Box, J. S. Hunter, W. G. Hunter, Statistics for Experimenters: An Introduction to Design, Data Analysis, and Model Building, 2nded, John Wiley and Sons., New York, (2010)

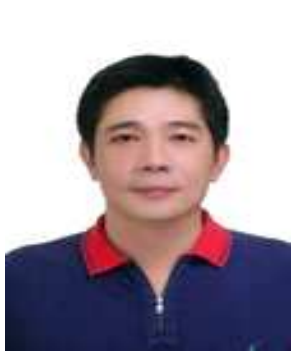

Yung-Tsan Jou received his Ph.D. degree in Integrated (ME, ISE) engineering from Ohio University, Athens, OH, in 2003. $\mathrm{He}$ is an Associate Professor of Industrial and Systems Engineering at Chung Yuan Christian University, Taiwan. His research has made contributions in green design, human-system interface design, senior assistive devices, and usability or quality evaluation by using virtual reality tools.

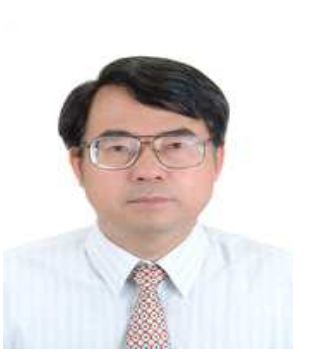

\section{Wen-Tsann}

Lin is a Distinguished Professor of Department of Industrial Engineering and Management at National Chin-Yi University of Technology, Taiwan. He received the Ph.D. degree from Department of Industrial Engineering in Chung-Yuan Christian University, Taiwan. His research interests include total quality management, MIS, service quality, and Six Sigma.

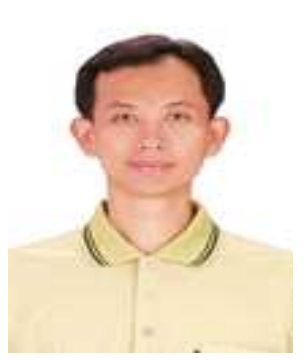

Wei-Cheng Lee is a Ph.D. student of Department of Industrial and Systems Engineering at Chung-Yuan Christian University, Taiwan. His research interests include DOE, quality management, and Six Sigma. is a Ph.D.

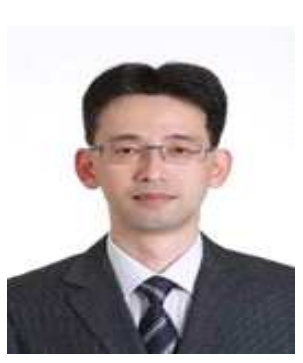

Tsu-Ming Yeh is an Associate Professor of Department of Industrial Engineering and Management at Dayeh University, Taiwan. He received the Ph.D. degree from Department of Industrial Engineering in Chung-Yuan Christian University, Taiwan. His research interests include Quality Management, Operation Management, Service Management. 